\title{
LabVIEW Based Software System: Quantitative Determination of Main Electronic Parameters for Schottky Junction Structures
}

\author{
O. ÇİÇEK and S. KURNAZ
}

\begin{abstract}
LabVIEW is a software development platform that can be programmed with a graphical interface and so, measurement and instrumentation problems are used to deliver a solution. In the sensor applications, it is very important to calculate the main electronic parameters of the produced samples and it takes a lot of time to calculate these parameters and evaluate results. Therefore, LabVIEW based software system was developed to minimize the time spent. In this way, it was used to make the analysis as fast as possible. This study aimed to calculate quickly the obtained results from the measurement system. For this purpose, AuPd/n-GaAs Schottky Junction Structure (SJS) was produced by using RF and DC sputtering techniques to investigate on electronic parameters of SJS. The forward and reverse current-voltage (I-V) of SJS at $\pm 3 \mathrm{~V}$ were measured at room temperature $(295 \mathrm{~K})$. By using thermionic emission (TE) theory, Ohm's law, Cheung and Cheung's function and modified Norde's function, the electronics parameters such as the series resistance $\left(R_{s}\right)$, the shunt resistance $\left(R_{s h}\right)$, the barrier height $\left(\Phi_{\mathrm{B} 0}\right)$ and the ideality factor $(n)$ were calculated and graphics, which were drawn according to these models, via the developed software platform.
\end{abstract}

Index Terms-LabVIEW, Current-Voltage, Electronic Parameters, Schottky Junction Structures.

\section{INTRODUCTION}

$\mathrm{R}$ ECENTLY, it has been focused seriously on semiconductor-based electronic circuit devices such as solar cells [1,2], light-emitting diodes [3], laser diodes [4], photodiodes [5], field-effect transistors [6], Schottky Junction Structures (SJSs) [7,8], etc.

Schottky junction structures (SJSs), which work at low

OSMAN ÇIÇEK, is with Department of Electrical and Electronics Engineering, Faculty of Engineering and Architecture, Kastamonu University, Kastamonu, Turkey, (e-mail: ocicek@kastamonu.edu.tr).

(iD) 0000-0002-2765-4165

SEDAT KURNAZ, is with Central Research Laboratory, Kastamonu University, Kastamonu, Turkey, (e-mail: sedatkurnaz@kastamonu.edu.tr).

(iD) 0000-0003-3657-2628

Manuscript received June 12, 2019; accepted July 2, 2019.

DOI: $\underline{10.17694 / \text { bajece. } 576303}$ forward voltages and have extremely fast switching capability, have attracted intense attention in the past few years owing to their potential application in electronics such as sensors, memory elements and rectifying devices [7,8]. In consequence of the potential barrier of SJSs, which is formed by tight contact with metal (M) and semiconductor (S), the rectifying devices are formed. Many researchers are interested in improving an electronic and optoelectronic performance of SJSs as inserting interfacial layer. Many parameters such as surface preparation process, barrier height, interfacial homogeneity, density of interfacial and dislocations, impurities, applied voltage and series resistance $\left(R_{s}\right)$ are important in rectifying devices $[9,10]$. For calculating the main electronic properties from I-V measurement there are many techniques such as the thermionic emission (TE) theory, the Ohm's law, the Cheung and Cheung's function and the modified Norde's functions [11-14].

Virtual Instruments (VIs) in LabVIEW is used to build a Graphical User Interface (GUI) as the time-saving $[15,16]$. At the same time, it is very useful in terms of accuracy and reliability of the results. It has replaced the conventional programming languages, and also it comes with an effective user interface. In this way, LabVIEW is used many industries such as automotive, semiconductor, energy, aerospace, etc. [17]. Several researchers have used different ways to analyze the output characteristics of SJSs, using the MATLAB $[18,19]$.

In light of these information, Au-Pd/n-GaAs SJS was produced by using DC and RF sputter. LabVIEW based program was developed to calculate these parameters and evaluate the results from I-V measurement. Then, the main electronic parameters of SJS were calculated and the obtained results were evaluated. Finally, it was found that the main electronic parameters of SJS were compatible with literature and the program was seen to work properly and reliably.

\section{EXPERIMENTAL PROCEDURE}

\section{A. Measurement System}

Au-Pd/n-GaAs SJS produced using RF and DC sputtering techniques, current-voltage (I-V) were measured in the measurement system for the characterized sensor applications under various conditions (Fig. 1). This system is also used for gas sensing measurements. It consists of Wayne Kerr 6500B, 
Keithley 2400, LakeShore 325, Alicat MFC, Scientech SF300A and vacuum chamber. Current-voltage (I-V), capacitance-time (C-t), capacitance-voltage (C-V), currenttime (I-t), etc. are measured depending on time, temperature, light and gas concentration.

\section{B. LabVIEW based software system}

LabVIEW is system engineering software that is used in applications that require testing, measurement and control. In spite of text-based programming, LabVIEW uses dataflow programming. Additionally, instead of writing line-by-line code in conventional programming such as $\mathrm{C}, \mathrm{C}++$, python, etc., it uses graphical icons. In this way, a user interface is created with tools and objects. The user interface is known as the front panel. To control front panel objects, you add code using the graphical objects of the functions. The block diagram contains this code. There is a dataflow of the application, here. LabVIEW programs are also called VIs, because it simulates physical instruments such as oscilloscope and multimeter using the graphical objects in the front panel interface. Each VI uses functions that process the input from the user interface or other sources, and display it, or move it to other files or other computers [20].

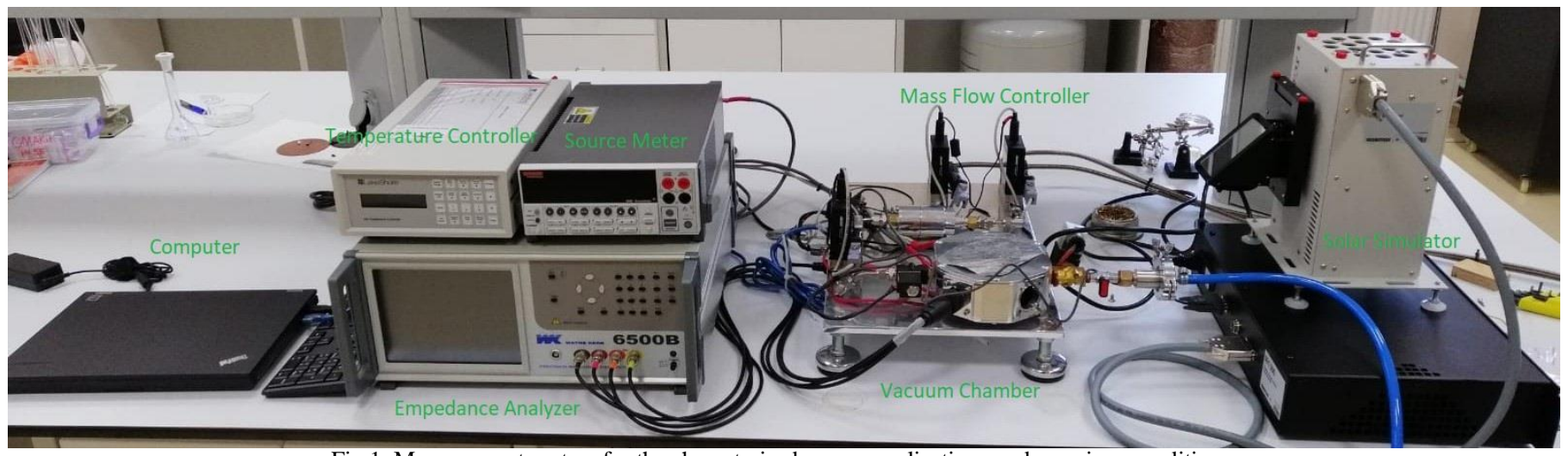

Fig.1. Measurement system for the characterized sensor applications under various conditions.

\section{Mathematical Background}

The TE theory, the Ohm's law, the Cheung and Cheung's function and the modified Norde's function are used in literature for calculating the main electronics parameters such as the shunt resistance $\left(R_{s h}\right)$, the series resistance $\left(R_{s}\right)$, the barrier height $\left(\Phi_{\mathrm{B} 0}\right)$ and the ideality factor $(\mathrm{n})$. The purpose of these models is to obtain valid and reliable results and also to compare the results with each other. According to the TE model, its parametric equations (1-4) are used.

$$
\begin{aligned}
& I=I_{o}\left[\exp \left(\frac{q\left(V-I R_{s}\right)}{n k T}\right)-1\right] \\
& I_{o}=A A^{*} T^{2} \exp \left(-\frac{q \Phi_{B 0}}{k T}\right) \\
& n=\frac{q}{k T}\left(\frac{d V}{d(\ln I)}\right) \\
& \Phi_{B 0}=\frac{k T}{q} \operatorname{In}\left(\frac{A A^{*} T^{2}}{I_{o}}\right)
\end{aligned}
$$

Here, the parameters denoted by $\mathrm{I}_{\mathrm{o}}, \mathrm{n}, \mathrm{q}, \mathrm{V}, \mathrm{IR}_{\mathrm{s}}, \mathrm{k}, \mathrm{T}, \Phi_{\mathrm{B} 0}, \mathrm{~A}$ and $A^{*}$ can be expressed as the saturation current, the ideality factor, the charge of electron, the applied bias voltage on the structure, the voltage drop on the series resistance $\left(R_{s}\right)$, the Boltzmann's constant, the temperature, the zero-bias barrier height, the rectifier contact area and the effective Richardson constant, respectively.

For Ohm's law, Eq. 5 is used to calculate $\mathrm{R}_{\mathrm{s}}$ (at maximum $\mathrm{V}$ ) and $\mathrm{R}_{\mathrm{sh}}$ (at minimum $\mathrm{V}$ ) from the $\mathrm{I}-\mathrm{V}$ measurement, respectively.

$R_{i}=\frac{d V_{i}}{d I_{i}}$

The other method to calculate the $R_{s}$ values of SJS is the Cheung and Cheung's function which has been acquired from the forward-bias of I-V measurement. The following equations are referred to as the Cheng and Cheng's functions in the literature.

$$
\begin{aligned}
& \frac{d V}{d(\ln I)}=I R_{s}+\left(\frac{n k T}{q}\right) \\
& H(I)=V-\frac{n k T}{q} \ln \left(\frac{I}{A A^{*} T^{2}}\right)=I R_{s}+n \Phi_{\text {в }}
\end{aligned}
$$

The modified Norde's function is another method to determine $\Phi_{\mathrm{B} 0}$ and $\mathrm{R}_{\mathrm{s}}$ values of the SJS.

$$
F(V)=\frac{V}{\gamma}-\frac{k T}{q} \ln \left(\frac{I(V)}{A A^{*} T^{2}}\right)
$$


where is greater than $n$ values. $F(V)-V$ graphs have minimum points of $\mathrm{V}_{\min }$ and $\mathrm{I}_{\min }$ values which use calculating $\Phi_{\mathrm{B} 0}$ and $\mathrm{R}_{\mathrm{s}}$ values from Eq. (8a) and (8b).

$$
\begin{aligned}
& \Phi_{B 0}=F\left(V_{\min }\right)+\frac{V_{\min }}{\gamma}-\frac{k T}{q} \\
& R_{s}=\frac{(\gamma-n) k T}{q I_{\min }}
\end{aligned}
$$

\section{RESULTS AND DISCUSSION}

The electrical characteristics of the prepared AuPd / n-GaAs MS type SJS under dark conditions were measured by the use of a Keithley 2400 Sourcemeter at $\pm 3 \mathrm{~V}$ by $20 \mathrm{mV}$ steps at in room temperature $(295 \mathrm{~K})$. The basic electrical parameters of SJSs $\left(\Phi_{\mathrm{Bo}}, \mathrm{n}, \mathrm{I}_{\mathrm{o}}, \mathrm{R}_{\mathrm{s}}, \mathrm{R}_{\mathrm{sh}}\right.$, etc.) were calculated from the I-V data via a developed Labview software program, which was formed from mathematical expressions of TE, Ohm's law, Cheung method and modified Norde method.

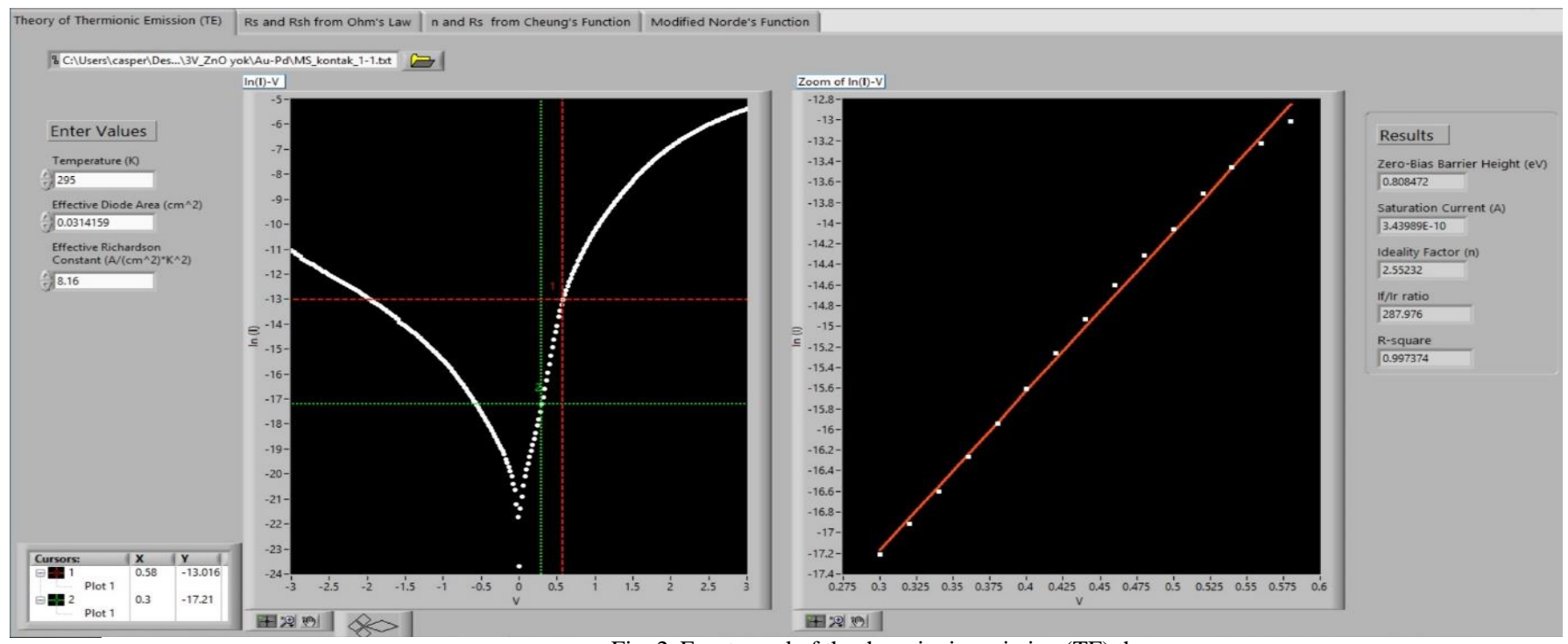

Fig. 2. Front panel of the thermionic emission (TE) theory

Utilizing the developed LabVIEW based program, the output of TE program was obtained from the using the source $\mathrm{I}-\mathrm{V}$ data and the input parameters such as temperature $(\mathrm{K})$, effective contact area $\left(\mathrm{cm}^{2}\right)$, the effective Richardson constant $\left(\mathrm{A} / \mathrm{cm}^{2}-\mathrm{K}^{2}\right)$ (Fig.2).

The data obtained from the measurement system is defined in the first section. Because the current values under forward or reverse bias voltage are important for modeling. In the second section, by using the separated data, the parameters are determined according to the formulas mentioned above.

In Fig. 3, for Ohm's law, another algorithm can be seen to obtain the $R_{s}$ and $R_{s h}$ values obtained from the forward and reverse biases regions of the I-V characteristics of SJS.

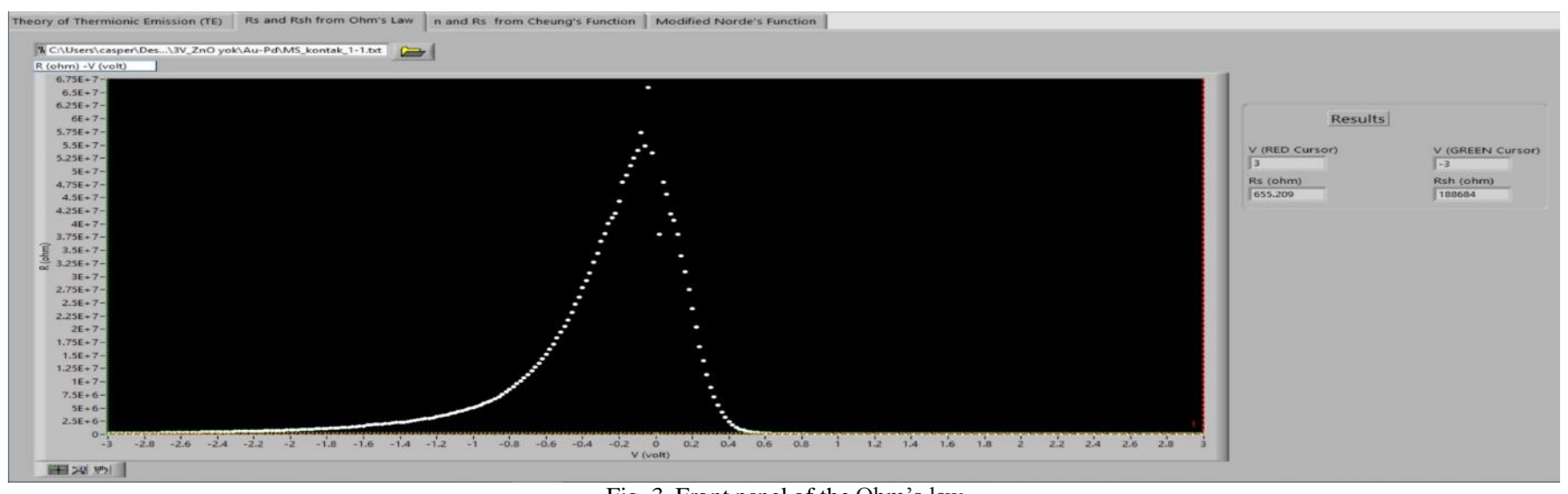

Fig. 3. Front panel of the Ohm's law

The other calculation methods for main electronic parameters are the Cheung and Cheung's function and the modified Norde's function are shown and drawn in Fig. 4 and 5 , respectively. To explain how the program works, first select the file with I-V data. Secondly, input values such as temperature, contact area and Richardson constant are entered. By specifying the desired regions with 2 cursors, the program is executed. So, graphics are drawn according to these models and the main electronic parameters are calculated 


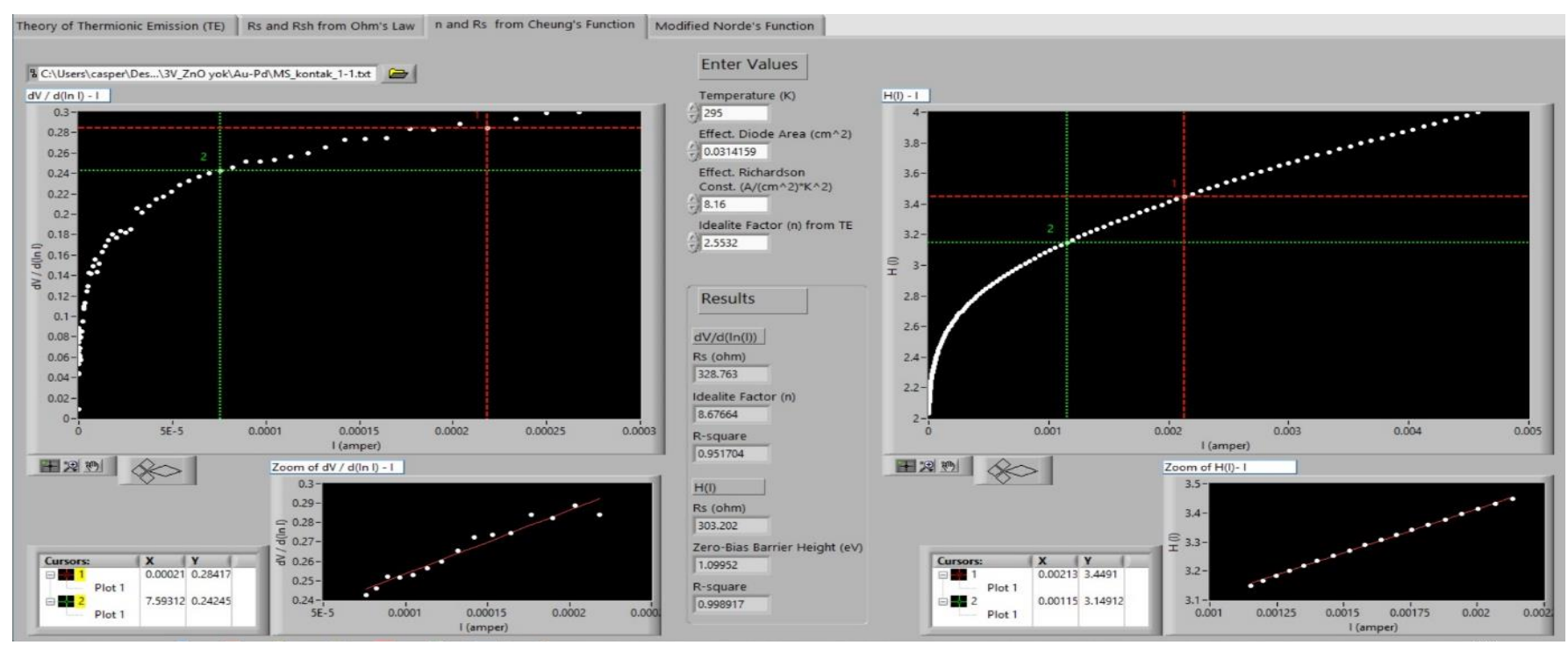

Fig. 4. Front panel of the Cheung and Cheung's function.
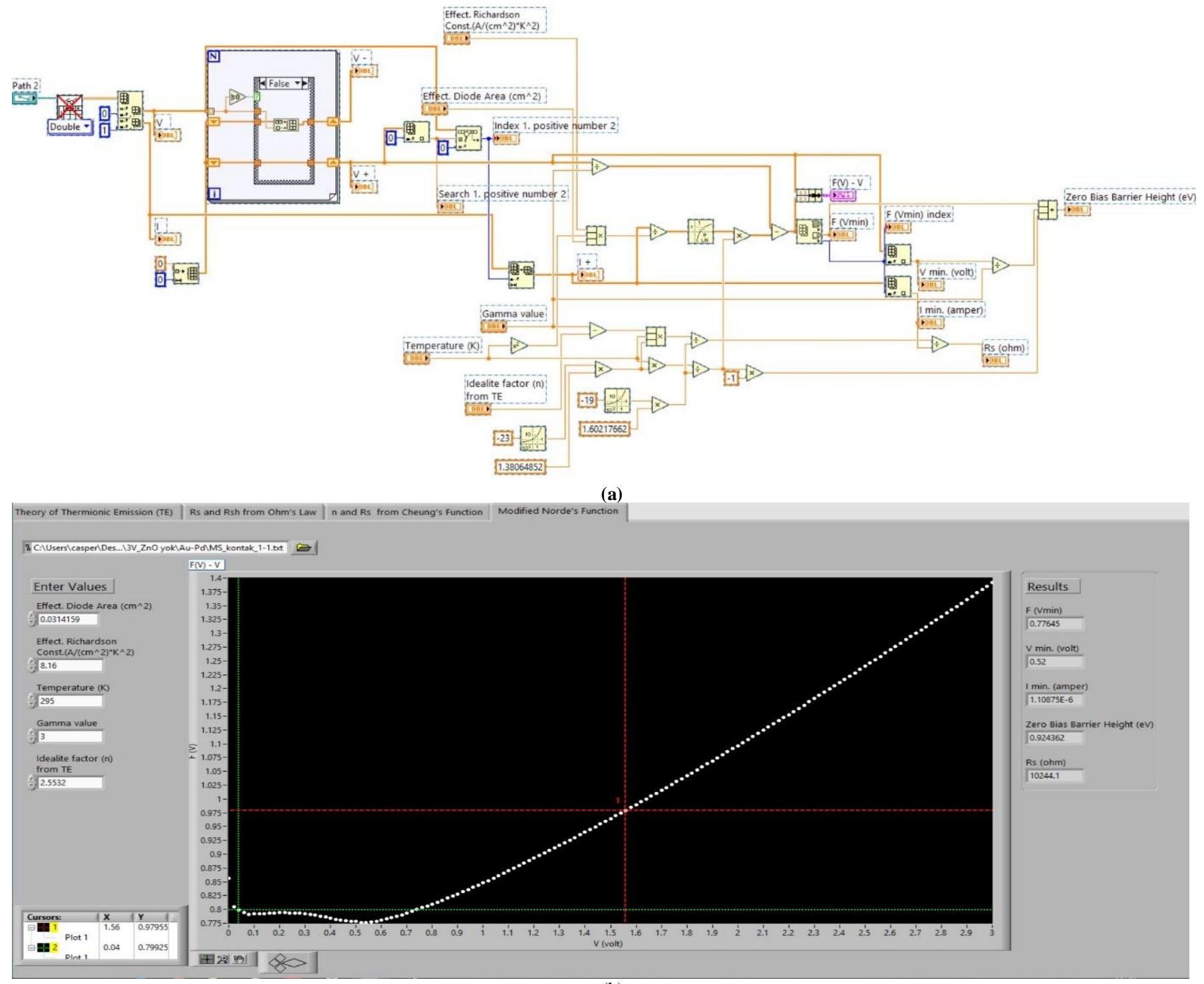

(b)

Fig. 5. Block diagram (a) and front panel (b) of the modified Norde's function in LabVIEW. 
The main electronic parameters of SJS, which are calculated different methods via the developed software program, are given in Table I. The results obtained from the program are almost consistent with the papers [8,21,22,23]. Minor differences in results could be referred to as many situations such as using GaAs crystals, impurity, barrier inhomogeneity, image-force effect, series resistance, tunneling process and non-uniformity distribution of rectifier contact metal.

TABLE I

RESULTS OF SJS BY USING THE TE THEORY, THE OHM'S LAW, THE CHEUNG AND CHEUNG'S FUNCTION AND THE MODIFIED NORDE'S FUNCTION.

\begin{tabular}{|c|c|c|c|c|c|c|c|c|}
\hline \multicolumn{5}{|c|}{ from Theory of Thermionic Emission (TE) } & \multicolumn{4}{|c|}{ from Ohm's Law } \\
\hline$I_{o},[\mathrm{~A}]$ & $n$ & $\Phi_{B 0},[\mathrm{eV}]$ & $\mathrm{RR},\left[\mathrm{I}_{\mathrm{F}} / \mathrm{I}_{\mathrm{R}}\right]$ & $\mathrm{R}^{2}$ & \multicolumn{2}{|c|}{$\mathrm{R}_{\mathrm{s}},[\mathrm{K} \Omega]$} & \multicolumn{2}{|c|}{$\mathrm{R}_{\mathrm{sh}},[\mathrm{K} \Omega]$} \\
\hline $3.44 \times 10^{-10}$ & 2.55 & 0.808 & 287.9 & 0.997 & \multicolumn{2}{|c|}{0.655} & \multicolumn{2}{|c|}{188.684} \\
\hline \multicolumn{5}{|c|}{ from the Cheung and Cheung's function } & \multicolumn{4}{|c|}{ from modified Norde's function } \\
\hline \multicolumn{3}{|c|}{$d V / d \ln I(\Omega)$} & \multicolumn{2}{|c|}{$H(I)-I(\Omega)$} & & & & \\
\hline $\mathrm{R}_{\mathrm{s}},[\Omega]$ & $\mathrm{R}^{2}$ & $\mathrm{R}_{\mathrm{s}}[\Omega]$ & $\Phi_{\mathrm{B} 0},[\mathrm{eV}]$ & $\mathrm{R}^{2}$ & $\mathrm{~F}\left(\mathrm{~V}_{\min }\right),[\mathrm{V}]$ & $\mathrm{V}_{\min },[\mathrm{V}]$ & $\Phi_{\mathrm{Bo}},[\mathrm{eV}]$ & $\mathrm{R}_{\mathrm{s}},[\mathrm{K} \Omega]$ \\
\hline 328.76 & 0.952 & 303.202 & 1.099 & 0.999 & 0.776 & 0.52 & 0.924 & 10.244 \\
\hline
\end{tabular}

\section{CONCLUSION}

Our main goal is to prevent time loss by developing a Labview based software system and shortening the analysis time. For this purpose, a program was developed to analyze Schottky junction structures (SJSs) according to many different models. The block diagram is shown in detail in this paper. Graphical user interfaces (front panels) are designed in LabVIEW. In this context, AuPd/n-GaAs MS type SJS was produced by using RF and DC sputtering techniques. I-V measurement was done. Then, according to the TE theory, the Ohm's law, the Cheung and Cheung's function and the modified Norde's function, this program is executed in this work to draw the collected data (I-V) of SJS from the photovoltaic measurement system. The main electronic parameters are obtained in a short time. The results are consistent with the literature. This indicates that the program works correctly and reliably.

\section{ACKNOWLEDGMENT}

The authors would like to thank Kastamonu University, Central Research Laboratory and its research team for its supports and contributions during this study. At the same time, a little part of this study was presented at the International Congress on Engineering and Life Science (ICELIS) 2019 symposium in Kastamonu/TURKEY.

\section{REFERENCES}

[1] H. Šamić, S. Makham, "The Influence of Radiation on the Solar Cell Efficiency.pdf (2)," Balkan Journal of Electrical and Computer Engineering, vol. 2, no. 1, 2014, pp. 2-5.

[2] N. Ekren, "Researches on Anti-Reflection Coating (ARC) Methods Used in PV Systems," Balkan Journal of Electrical \& Computer Engineering, vol. 6 , no. 1, 2018, pp.42-46.

[3] S. Shin, J. Kim, Y.-H. Kim, S.-I. Kim. "Enhanced performance of organic light-emitting diodes by using hybrid anodes composed of graphene and conducting polymer," Current Applied Physics, vol. 13, no. 2, 2013, pp. 144-147.

[4] A. Ugur and M. Yilmaz, "A GaN-Based Synchronous Buck Converter for High Power Laser Diode Drive Applications," Balkan Journal of Electrical \& Computer Engineering, vol. 6, no. 1, 2018, pp. 62-68.

[5] T. Knežević, X. Liu, E. Hardeveld, T. Suligoj and L. K. Nanver, "Limits on Thinning of Boron Layers With/Without Metal Contacting in PureB Si (Photo)Diodes," IEEE Electron Device Letters, vol. 40, no. 6, June 2019, pp. 858-861.
[6] Y. Lan et al., "Flexible Graphene Field-Effect Transistors with Extrinsic $\mathrm{f}_{\max }$ of $28 \mathrm{GHz}$," IEEE Electron Device Letters, vol. 39, no. 12, Dec. 2018, pp. 1944-1947.

[7] S. O. Tan, H. Uslu Tecimer, O. Çiçek, H. Tecimer, İ. Orak and Ş. Altındal, "Electrical characterizations of $\mathrm{Au} / \mathrm{ZnO} / \mathrm{n}-\mathrm{GaAs}$ Schottky diodes under distinct illumination intensities," Journal of Material Science: Material Electron, vol. 27, no. 8, 2016, pp. 8340-8347.

[8] O. Çiçek, H. Uslu Tecimer, S. Tan, H. Tecimer, Ş. Altındal and I. Uslu, "Evaluation of electrical and photovoltaic behaviors as comparative of $\mathrm{Au} / \mathrm{n}-\mathrm{GaAs}(\mathrm{MS})$ diodes with and without pure and graphene (Gr)-doped polyvinyl alcohol (PVA) interfacial layer under dark and illuminated conditions, "Composites Part B, vol. 98, 2016, pp. 260-268.

[9] Ü. Özgür, Y. I. Alivov, A. Teke, M. A. Reshchikov, S. Doğan, V. Avruti, S. J. Cho and H. Morkoç, "A comprehensive review of $\mathrm{ZnO}$ materials and devices," Journal of Applied Physics, vol. 98, no. 4, 2005, 041301.

[10] F. Z. Pür ve A. Tataroğlu, "Analysis of the series resistance and interface states of $\mathrm{Au} / \mathrm{Si}_{3} \mathrm{~N}_{4} / \mathrm{n}-\mathrm{Si}$ (metal-insulator-semiconductor) Schottky diodes using IV characteristics in a wide temperature range," Physica Scripta, vol. 86, no. 3, 2012.

[11] S.K. Cheung and N.W. Cheung, "Extraction of Schottky diode parameters from forward current-voltage characteristics," Applied Physics Letters, vol. 49, no. 2, 1986, pp. 85-87.

[12] H. Norde, "A modified forward I-V plot for Schottky diodes with high series resistance," Journal of Appied Physics, vol. 50, no. 7, 1979, pp.5052-5053.

[13] K. E. Bohlin, "Generalized Norde plot including determination of the ideality factor," Journal of Applied Physics, vol. 60, 1986.

[14] S. M. Sze, "Semiconductor Devices: Physics and Technology," New Tork: Wiley, 1985

[15] J. Travis and J. King, "LabVIEW for Everyone: Graphical Programming Made Easy and Fun", 2006.

[16] R. Bitter, T. Mohiuddin, and M. Nawrocki, "LabVIEW: Advanced programming techniques". Crc Press, 2006.

[17] LabVIEW applications by 2019 Viewpoint Systems, Inc., Available: https://www.viewpointusa.com/labview/where-is-labview-used-whouses-it-companies-that-use-it/, [Jun 5, 2019].

[18] T. Salmi, M. Bouzguenda, A. Gastli and A. Masmoudi, "MATLAB/Simulink Based Modelling of Solar Photovoltaic Cell," International Journal of Renewable Energy Research, vol. 2, no. 2, 2012.

[19] S. Nema, R.K. Nema and G. Agnihotri, "MATLAB/Simulink based study of photovoltaic cells/modules /array and their experimental verification", International Journal of Energy and Environment, vol. 1, no. 3, 2010.

[20] LabVIEW User Manuel, National Instruments, 2003.

[21] Ş. Karataş and A. Turut, "The determination of electronic and interface state density distributions of Au/n-type GaAs Schottky barrier diodes," Physica B, vol. 381, 2006, pp. 199-203.

[22] M. Soylu and F. Yakuphanoğlu, "Photovoltaic and interface state density properties of the Au/n-GaAs Schottky barrier solar cell," Thin Solid Films, vol. 519, 2011, pp. 1950-1954.

[23] A. Bobby, N. Shiwakoti, P. S. Gupta and B. K. Antony, "Barrier modification of $\mathrm{Au} / \mathrm{n}-\mathrm{GaAs}$ Schottky structure by organic interlayer," Indian Journal of Physics, vol. 90, no. 3, 2006, pp.307-312. 


\section{BIOGRAPHIES}

OSMAN ÇiçEK Bozkır, Konya, in 1986. He received the bachelor's degrees in the Electrical Teaching Department from Gazi University, and the M.S. and Ph.D. degrees in Electrical and Electronics Engineering Department from Karabük University, Karabük, Turkey, in 2013 and 2016, respectively.

From 2011 to 2016, he was a lecturer with the Department of Electrical and Energy, Kastamonu University, Since 2017, he has been an Assistant Professor with the Electrical and Electronics Engineering Department, Kastamonu University. He is the author of more than 15 articles, and more than 10 projects. His research interests include solar cells and applications, enhancing the performance of solar cells, Schottky junction structures, and innovation sensor applications.

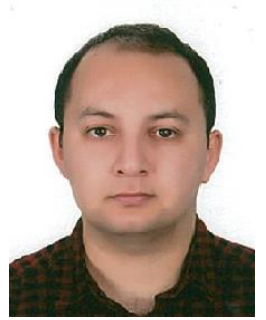

SEDAT KURNAZ Alaçam, Samsun, in 1989. He received the B.S. degrees in the Physics Engineering Department from Hacettepe University in 2013 and the M.S. degrees in Physics Department from Karadeniz Technical University in 2016. He has been a lecturer at Central Research Laboratory, Kastamonu University since 2017. He continues his Ph.D. at Kastamonu University. His main research interests are superconductor and semiconductor materials, thin film deposition, Schottky junction structures, solar cells. 